\title{
ERRATUM
}

Re: Cardiovasc Intervent Radiol (1999) 22: 7-12: Due to an inadvertent printer's error, this article was originally published with substantial text omissions. The corrected version of the article appears below in its entirety.

\section{Brain "Embolism" Detected by Magnetic Resonance Imaging During Percutaneous Mitral Balloon Commissurotomy}

\author{
Paulo Rocha, ${ }^{1}$ Salah D. Qanadli, ${ }^{2}$ Pierre Strumza, ${ }^{3}$ Safia Kacher ${ }^{4}$ Linda Aberkane,${ }^{4}$ \\ Pierre Aubry, ${ }^{4}$ Michel Rigaud, ${ }^{4}$ Pascal Lacombe, ${ }^{2}$ Bernadette Raffestin ${ }^{1}$
}

\footnotetext{
${ }^{1}$ Department of Physiology, Hôpital Ambroise Paré, Université René Descartes, 9 av Charles de Gaulle, 92100 Boulogne, Billancourt, France

${ }^{2}$ Department of Radiology, Hôpital Ambroise Paré, Université René Descartes, 9 av Charles de Gaulle, 92100 Boulogne, Billancourt, France

${ }^{3}$ Department of Anesthesiology, Hôpital Ambroise Paré, Université René Descartes, 9 av Charles de Gaulle, 92100 Boulogne,

Billancourt, France

${ }^{4}$ Department of Cardiology, Hôpital Ambroise Paré, Université René Descartes, 9 av Charles de Gaulle, 92100 Boulogne, Billancourt, France
}

\section{Abstract}

Purpose: The common finding of thrombi between the bifoil balloons when they were extracted after mitral dilation prompted us to look for evidence of minor brain embolisms using the sensitive technique of BMRI (brain magnetic resonance T2-weighted imaging).

Methods: BMRI was performed within $48 \mathrm{hr}$ before and after a percutaneous mitral balloon commissurotomy (PMBC) in each of the 63 patients in this study.

Results: There was evidence (hyperintensity foci: $\mathrm{HI}$ ) of a previous asymptomatic brain embolism in 38 of 63 patients before PMBC and a new HI appeared in 18 of 63 patients after the procedure. New HI signals were found exclusively in the white matter in 8 of 18 patients and in only 3 of 18 were $\mathrm{HI}$ signs larger than $1 \mathrm{~cm}$. One patient, with an $\mathrm{HI}$ signal $>1 \mathrm{~cm}$ in the thalamus and another $<1 \mathrm{~cm}$ in the brain stem, presented diplopia accompanied by other minor clinical signs. The differences in HI rate among four subgroups ( 1 , older vs younger than 43 years; 2 , sinus rhythm vs atrial fibrillation; 3 , echo score $<8$ vs $>8 ; 4$, patients from western countries vs the others) were not statistically significant, probably because the number of patients in each subgroup was low. Patients in atrial fibrillation had slightly more (not

Correspondence to: P. Rocha M.D. significant) HI before PMBC $(15 / 20,75 \%)$ than patients in sinus rhythm $(23 / 43,53 \%)$, but after PMBC their HI frequencies were similar (atrial fibrillation: $5 / 20,25 \%$; sinus rhythm: $13 / 43,30 \%$ ).

Conclusion: Brain microembolism is frequent during PMBC, but is often anatomically limited and free from clinical signs in most cases. Brain embolism seems to be related mainly to the procedure itself and not the features of the patient.

Key words: Percutaneous mitral balloon commissurotomy-Brain magnetic resonance imaging-Brain embolism

In western countries (defined as European countries, Canada, and USA), strokes complicated $1 \%-4 \%$ of percutaneous mitral balloon commissurotomy (PMBC) procedures before 1990 [1-3]. The stroke rate decreased after the introduction of transesophageal echocardiography before each PMBC, found useful to rule out atrial thrombi.

The common finding [4] of thrombi between the two balloons of the bifoil catheter-balloons when pulled back after the procedure, prompted us to search for minor stroke signs in patients without neurologic evidence of brain embolism. Brain magnetic resonance imaging (BMRI) is a very sensitive tool for detecting brain microembolisms. However, BMRI hyperintensity foci (HI) are not exclusively deter- 
mined by embolisms. A previous paper [5] presented the first 27 patients in this series of 63 . Since then our HI rate following PMBC has decreased.

The purposes of this study were to assess the clinical and subclinical stroke rate during PMBC and to analyze the possible causes of $\mathrm{HI}$.

\section{Materials and Methods}

BMRI was carried out in 63 patients within $48 \mathrm{hr}$ before and after PMBC. Informed consent was obtained in all cases after a full explanation of the BMRI investigation. All 63 patients had symptomatic rheumatic mitral stenosis and their mitral valve areas (MVA), assessed by transthoracic two-dimensional echocardiography, by Doppler, or by Gorlin's hemodynamic formula, were $<1.5$ $\mathrm{cm}^{2}$. Thirty-two patients were in class II and 31 in class III of the New York Heart Association functional classification. Patient heart rhythms were: sinus rhythm in 43 patients and atrial fibrillation in the remaining 20 . Mean age was $43 \pm 15$ years and 51 patients were women. About $46 \%$ (29/63) of patients came from western countries, the others from various countries with poorer social and medical structures than western countries. Seven patients had had a previous closed surgical mitral commissurotomy $14 \pm 8$ years before. The mean echographic score [6] was $7.7 \pm 1.9$, and subvalvular disease was the most common anatomic impairment. Mitral regurgitation, according to Sellers' classification, was $1+$ in 19 patients and $2+$ in six patients; the others had no mitral regurgitation.

Transesophageal echocardiography, which is more sensitive than transthoracic echocardiography [7] in detecting thrombi in the left appendage, was performed within $48 \mathrm{hr}$ before each mitral dilation. Our PMBC technique has already been extensively described [8]. A diagnostic heart catheterization study was carried out immediately before PMBC and a second hemodynamic study, assessing the efficacy of PMBC, was performed immediately after the procedure. In all cases, balloons crossed the stenotic valve on the anterograde route by transseptal catheterization. In the first 27 patients their usual anticoagulation treatment was stopped before PMBC and $35 \mathrm{IU} / \mathrm{kg}$ i.v. heparin administered after transseptal catheterization. In the remaining patients their usual anticoagulation treatment was maintained.

Bifoil catheter-balloons (Bifoil Twin-AT balloon, Mansfield, Boston Scientific, Watertown, MA, USA) were initially used in 15 patients and Inoue balloons ( 28 or $30 \mathrm{~mm}$; Meditor, Hoenheim, France) in 52 patients. Bifoil balloons were replaced four times by Inoue balloons due to bifoil instability.

The HI rates were compared in four subgroups according to: (1) cardiac rhythm: patients in sinus rhythm compared with patients in atrial fibrillation; (2) age: older patients compared with those younger than the mean group age; (3) patient's origin: patients from western countries compared with patients from other countries; and (4) mitral valve status: patients with an echographic score lower than 8 compared with the others (Table 1).

BMRI was carried out using a median field $(0.5 \mathrm{~T})$ with $8-\mathrm{mm}$ deep axial slices. The sequence, similar for all patients, was: spin echo (SE) T2-weighted magnetic resonance images $(\mathrm{TR}=2020$ $\mathrm{msec}, \mathrm{TE}=60 / 120 \mathrm{msec}$ ).

\section{Statistics}

Data are presented as mean \pm standard deviation. Comparisons of MVA before and after PMBC were made using the paired Student's $t$-test. Comparisons of $\mathrm{HI}$ rates in the different patient subgroups were made with the chi-squared test. A probability value of $<0.05$ was considered significant.

\section{Results}

PMBC was successful in 58 of 63 patients. Five PMBCs were unsuccessful, in three patients because the procedure was complicated by major mitral regurgitation and in two patients because the MVA remained $<1.5 \mathrm{~cm}^{2}$. MVA values, patients' characteristics, and HI rates are presented in Table 1. MVA values were similar to those obtained in our 400 other PMBCs [8]. The total duration of the catheterization was $98 \pm 40 \mathrm{~min}$ and the time necessary for the PMBC itself, from the beginning of transseptal catheterization to the last balloon inflation, was $24 \pm 6 \mathrm{~min}$.

HI suggesting brain embolism, multiple or isolated, were found on BMRI in 38 of 63 patients before PMBC. The HI dimensions were smaller than $1 \mathrm{~cm}$ in all but three patients. New HI were found in 18 of 63 patients after mitral dilation. These new HI were $<1 \mathrm{~cm}$ (Fig. 1) in 15 of 18 patients. The PMBC procedure itself lasted $27 \pm 4 \mathrm{~min}$ in patients with new HI signals and $22 \pm 4 \mathrm{~min}$ for the others [not significant (NS)].

The new HI signals were exclusively in the white matter in eight of 18 patients. Three HI were exclusively in the cortical area: one in the right, one in the left frontal lobes, and in a last patient two new HI were observed, both in the left cortical superior parietalis gyrus (Fig. 2). These new HI locations are presented in Table 2.

Only three of the 18 new HI were larger than $1 \mathrm{~cm}$ and they were accompanied by neurologic symptoms in two patients. One patient, with a $\mathrm{HI}$ signal $>1 \mathrm{~cm}$ in the thalamus and another $<1 \mathrm{~cm}$ in the brain stem, presented diplopia for $24 \mathrm{hr}$ accompanied by other minor clinical signs. The other symptomatic patient, with an $\mathrm{HI}$ in the corpus callosum, suffered a short convulsive fit during the first catheterization study.

Patients whose PMBC was carried out with bifoil balloons tended to have a higher rate of post-procedural HI, but the bifoil and Inoue subgroups were not comparable. First, the tendency to a higher rate of $\mathrm{HI}$ in the bifoil subgroup was already present before PMBC, these patients being older, more often in atrial fibrillation, and more often from western countries. Secondly, the PMBCs of patients from the bifoil group were performed earlier (always before 1993) and patients from the bifoil subgroup received heparin whereas the others did not. Nevertheless, data on the PMBCs and BMRIs carried out with bifoil balloons and Inoue balloons are presented, for information, in Table 1.

HI rates between various subgroups were not statistically different in spite of a trend toward higher post-procedural $\mathrm{HI}$ in the subgroup of western patients. 


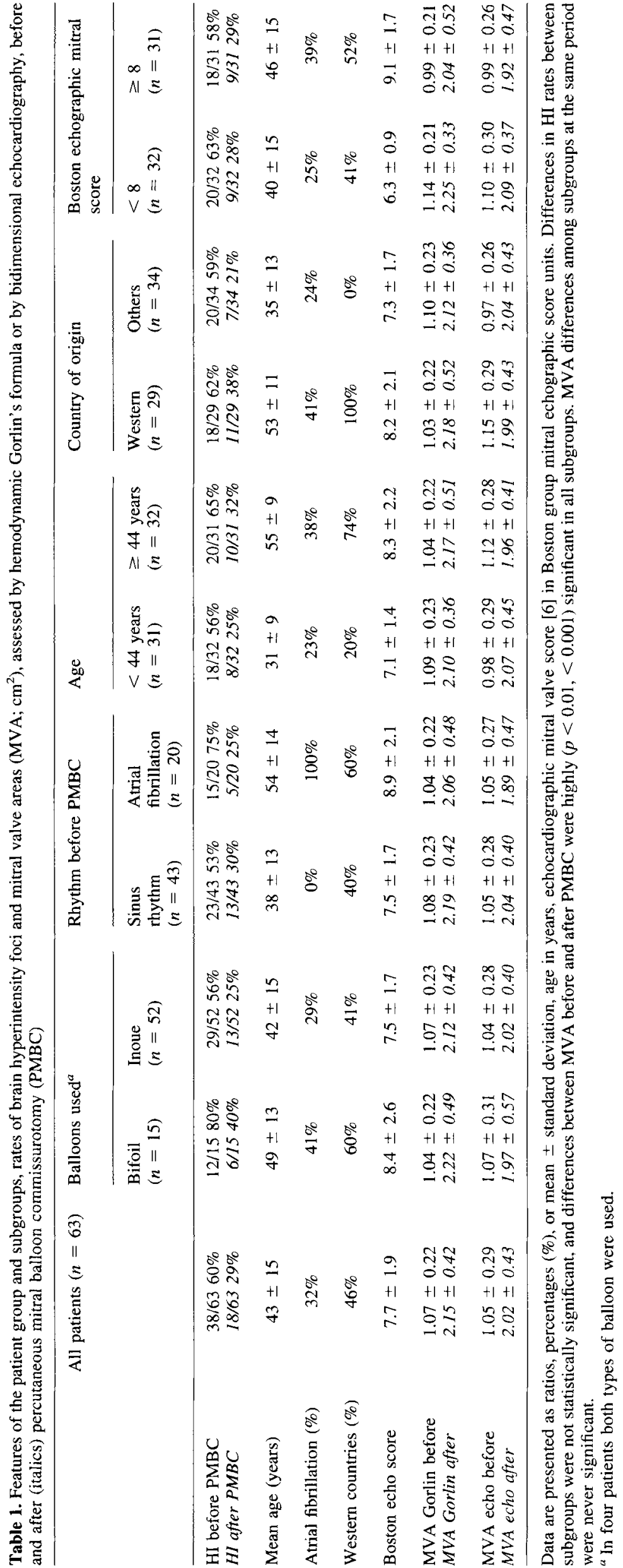



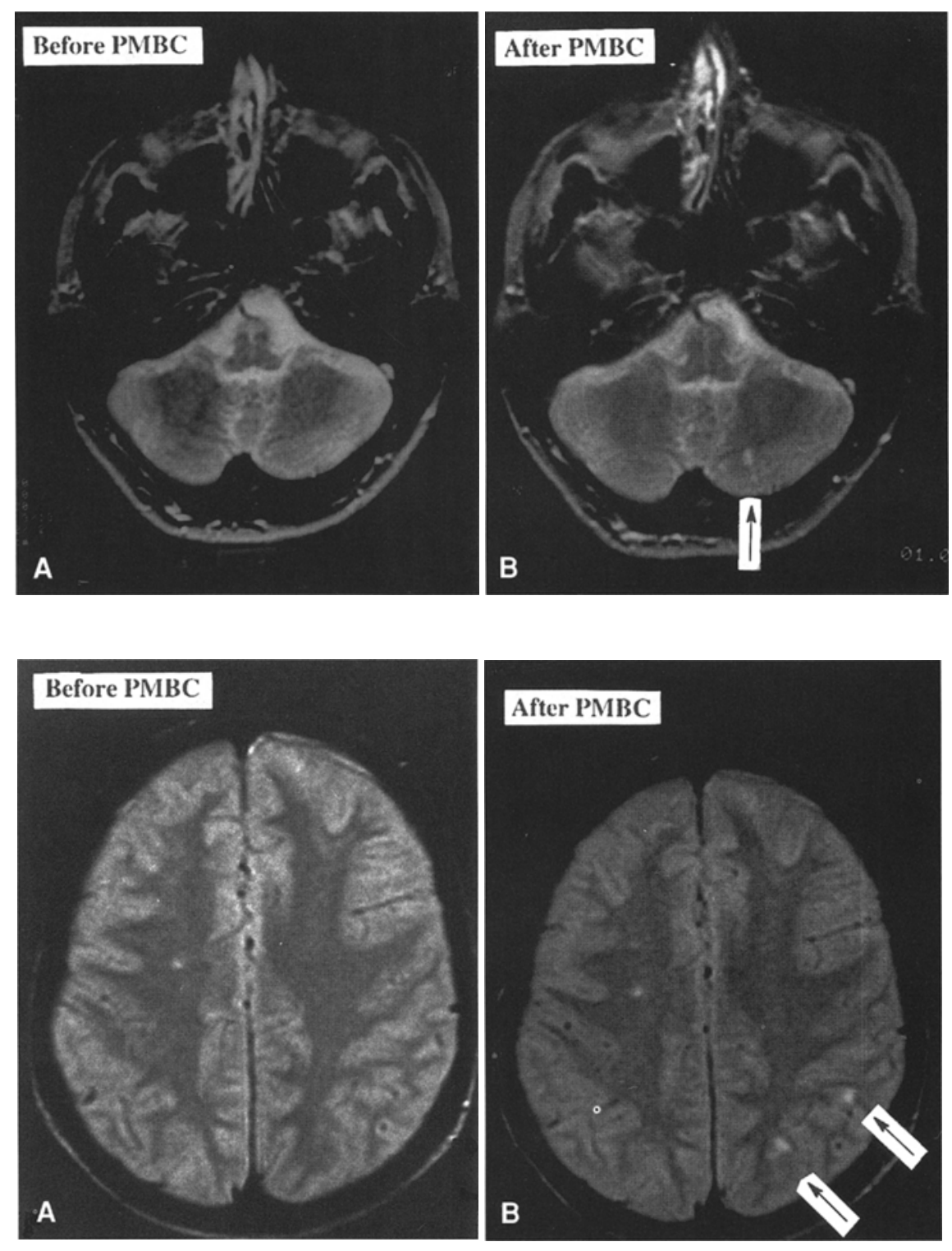

Fig. 2. Spin-echo T2-weighted brain magnetic resonance (BMRI) scan ( $\mathrm{TR}=2020 \mathrm{msec}, \mathrm{TE}=60 \mathrm{msec}$ ) in a 21-year-old woman. A Before percutaneous mitral balloon commissurotomy (PMBC), BMRI showed a hyperintensity focus in the right semiovale centrum. Two new hyperintensity foci appeared in the left superior parietalis gyrus (arrows on B) $48 \mathrm{hr}$ after PMBC.
MVA values prior to and after PMBC were similar for all subgroups: about $1 \mathrm{~cm}^{2}$ before and $2 \mathrm{~cm}^{2}$ after PMBC. However, patients from the subgroup with an echographic mitral valve score $<8$ showed a clear trend (NS) to a larger MVA after PMBC (Table 1).

\section{Discussion}

As the time elapsed between the two BMRIs varied from 3 to 4 days, the new HI were more likely related to embolisms than to other causes.

The widespread use of transesophageal echocardiography before PMBC [7] reduced the stroke rate during this procedure $[9,10]$. Nevertheless, this reduced stroke rate was only clearly observed in studies where the authors performed more than 100 mitral dilations $[11,12]$, after the PMBC "learning curve". Otherwise, even if mortality and morbidity linked to PMBC decreased strongly after this "learning
Table 2. Locations of brain magnetic resonance hyperintensity foci (HI) following percutaneous mitral dilation

\begin{tabular}{llc}
\hline Brain structures & Right & Left \\
\hline Periventricular frontal lobe & 1 & 2 \\
Parietal lobe & 3 & 1 \\
Occipital subcortical lobe & 1 & \\
Peri-insular area & 1 & 3 \\
Cerebellum (Fig. 1) & & 1 \\
Lenticular nucleus & 2 & 2 \\
Frontal semiovale centrum & 2 HI in the same patient \\
Corpus callosum & & 1 \\
Brain stem & & \\
\hline
\end{tabular}

Two patients had $\mathrm{HI}$ in two new locations.

curve" period, the post-procedural MVA values obtained did not increase, remaining close to $2 \mathrm{~cm}^{2}$ [10-13].

Peripheral embolism during PMBC has always been less frequent in the East than in the West [14-16]. This lower 
stroke frequency could be connected to ethnic features, but not exclusively; in fact, even in western countries strokes became rarer after the introduction of transesophageal echocardiography before each procedure and the arrival of the Inoue balloon. The Inoue balloon [17] has been available in the East since 1984. Due to its characteristics [18] it requires fewer left atrial maneuvers, which may cause the displacement of left atrial thrombi or their fragmentation. In other respects, the procedure may be shorter with the Inoue balloon, since the bifoil balloon is more difficult to stabilize across the mitral valve until full bifoil inflation [19]. In fact, Chen et al. [20] successfully carried out PMBC in six patients with proven left appendage thrombi without noting clinical signs of embolism. Brain embolism is also rare when mitral dilation is performed without transseptal catheterization [21], which is consistent with the hypothesis of displacement of unsuspected left atrial thrombi as a cause of PMBC brain embolism.

\section{General Meaning of BMRI Hyperintensity Foci}

HI are not exclusively induced by embolism and may be linked to other pathologies such as postanoxic lesions, cytotoxic or vasogenic edema, astrocytic gliosis, atherosclerosis, systemic diseases, Behçet disease, or antiphospholipid syndrome; HI are also often observed in demyelinated perivascular areas, particularly in elderly $[22,23]$ and hypertensive patients. On the other hand, the HI features do not allow new embolisms to be distinguished from old ones. The short delay between BMRIs would rule out other HI etiologies. However, cardiac collapse or severe hypotension may complicate PMBC and might be the cause of new HI. That possibility deserves analysis.

Balloon inflation during PMBC, in particular when the balloon is of cylindrical shape such as the Inoue balloon, dramatically limits left ventricular filling. Nevertheless, its inflation followed by deflation can be accomplished within 10 sec. When bifoil balloons were used, their inflation and deflation times were much longer, sometimes exceeding 1 min. However, left ventricular filling, although decreased, was still possible during bifoil inflation, the blood passing through the gaps between the two bifoil balloons. In this group of 63 patients, hypotension under $60 \mathrm{mmHg}$ was seldom observed for more than $15 \mathrm{sec}$. Thus, we do not think that the 18 new HI could have been caused by hypotension.

\section{Hyperintensity Foci Before PMBC}

HI were detected in 38 patients before mitral dilation. They were multiple in many patients and, except in three patients, were $<1 \mathrm{~cm}$. One of the patients with $>1 \mathrm{~cm} \mathrm{HI} \mathrm{had} \mathrm{a}$ major, near-total, unihemispherical defect that was the result of a neonatal anoxic period. Mitral stenosis is a well-known embolizing pathology [24] and the high $\mathrm{HI}$ rate before $\mathrm{PMBC}$ is not surprising.

\section{Hyperintensity Foci after PMBC}

After PMBC, 18 patients showed new HI consistent with periprocedural embolisms. These new HI were usually smaller than $1 \mathrm{~cm}$ and were only twice followed by clear neurologic symptoms. A patient with the double location in the corpus callosum (genu and splenium), had a convulsive fit before transseptal catheterization, consequently needing a short and light general anesthetic. This embolism was simultaneous with diagnostic catheterization and, in this particular case, not related to the PMBC procedure itself. After PMBC the $\mathrm{HI}$ rates were statistically similar in all subgroups in spite of rhythm, but there was a clear trend towards higher $\mathrm{HI}$ in the subgroup of patients from western countries, who were older and had a more impaired mitral valve, often requiring a longer procedure. The recent decrease in HI rate could not be linked to better detection of left atrial thrombi, since the first PMBC patient of the present study was enrolled in 1991, long after the introduction in our department of transesophageal echocardiography before each PMBC.

BMRIs were carried out on three other patients before and after conventional diagnostic catheterization, and the second BMRI did not disclose new HI.

Most patients did not present post-procedural neurologic symptoms, but the neurologic clinical examinations were performed by cardiologists; perhaps a neurologist would have been able to find discreet neurologic clinical signs of embolism in these 18 patients.

\section{Strokes and $P M B C$}

Although frequent, strokes during PMBC seem less dramatic than strokes induced by atherosclerosis, death by stroke in the PMBC literature [1] being exceptional. In our 400 other PMBC procedures, seven patients had clinical signs of brain embolism; five were in the first half of the group. One month after PMBC, neurologic clinical signs persisted, although discreet, in only two of these seven patients. Clinical strokes have markedly decreased in our group since 1990 , following the introduction of transesophageal echocardiography in 1991 and after the exclusive use of Inoue balloons. However, these two reasons may not hold, because since then patients with major valve alterations have no longer been accepted for PMBC. After 1991, left atrial thrombi were detected in four patients. Images of all four thrombi vanished after 2 months of warfarin treatment and PMBC was successfully carried out on all patients.

Calcific embolisms have occasionally been reported during heart catheterization [25], or spontaneously in patients with heart valve disease [26]. The 18 new "embolisms" detected in our group of patients could hardly be explained by calcium dislodgment. In the literature, patients with calcium embolism had valvular aortic, not mitral, disease. On the other hand, only four of these 18 patients with new HI presented echographic evidence of mitral calcification. 


\section{Conclusion}

Brain embolism is not rare during percutaneous mitral balloon commissurotomy. Existing left atrial thrombi or clotting over the catheter balloon might be the origin of these embolisms. Brain microembolisms in this group of patients were well tolerated and not necessarily accompanied by symptoms, mostly when the hyperintensity foci in brain magnetic resonance images were smaller than $1 \mathrm{~cm}$. The reduced procedure duration, perhaps as a result of the exclusive use of Inoue balloons, could be one of the major causes of the recent decrease in the rate of microembolism.

\section{References}

1. Babic UU, Dorros G, Pejcic P, Djuristic Z, Vucinic M, Lewin R, Grujicic SN (1988) Percutaneous mitral valvuloplasty: Retrograde, transarterial double-balloon technique utilizing the transseptal approach. Cathet Cardiovase Diagn 14:229-237

2. Vahanian A, Michel PL, Cormier B, Vitoux B, Michel X, Slama M, Enriquez-Sarano L, Trabelsi S, Ben Ismail M, Acar J (1989) Results of percutaneous mitral commissurotomy in 200 patients. Am J Cardiol 63:847-852

3. Palacios I, Block PC, Wilkins GT, Weyman AE (1989) Follow-up of patients undergoing percutaneous mitral balloon valvotomy: Analysis of factors determining restenosis. Circulation 79:573-579

4. Berland J, Rocha P, Choussat A, Lefebvre T, Fernandez F, Rath P (1993) Balloon mitral valvotomy by using the Twin-AT catheter: Immediate results and complications in 110 patients. Cathet Cardiovasc Diag 28:126-133

5. Rocha P, Mulot R, Lacombe P, Pillière R, Belarbi A, Raffestin B (1994) Brain magnetic imaging before and after percutaneous mitral balloon commissurotomy. Am J Cardiol 74:955-957

6. Wilkins G, Weyman AE, Abascal V, Block P, Palacios I (1988) Percutaneous balloon dilation of the mitral valve: An analysis of echocardiographic variables related to outcome and the mechanism of dilation. Br Heart $\mathbf{J}$ 60:299-308

7. Cormier B, Serafini D, Grimberg D, Scheller B, Acar J (1991) Détection des thromboses de l'oreillette gauche du rétrécissement mitral: Intérêt particulier de l'échographie transoesophagienne. Arch Mal Coeur 84:1321-1326

8. Rocha P, Berland J, Rigaud M, Fernandez F, Bourdarias JP, Letac B (1991) Fluoroscopic guidance in transseptal catheterization for percutaneous mitral balloon valvotomy. Cathet Cardiovasc Diagn 23:172-176

9. Gerardin B, Losay J, Leriche H, Piot D, Petit J, Houyel L (1992) Valvulotomie mitrale percutanée: comparaison de deux techniques chez 100 patients appariés. Arch Mal Coeur 85:1797-1803

10. Chan C, Berland J, Cribier A, Rocha P, Stix G, Derumaux G, Letac B (1994) Results of percutaneous transseptal mitral commissurotomy in patients 40 years of age and above compared with those under 40 years of age: Immediate and 5-year follow-up results. Cathet Cardiovasc Diagn 32:223-230
11. Patel J, Vythilingum S, Mitha AS (1990) Balloon dilation of mitral valve by single bifoil $(2 \times 19 \mathrm{~mm})$ or trefoil $(3 \times 15 \mathrm{~mm})$ catheter. $\mathrm{Br}$ Heart J 64:342-346

12. Herrmann $\mathrm{H}$, Kleaveland $\mathrm{P}$, Hill JA, Cowley MJ, Margolis IR, Nocero MA, Zalewski A, Pepine CL (M-Heart Group) (1990) The M-Heart percutaneous mitral valvuloplasty registry. J Am Coll Cardiol 15:12211226

13. Tuzcu M, Block PC, Palacios IF (1991) Comparison of early versus late experience with percutaneous mitral balloon valvuloplasty. J Am Coll Cardiol 17:1121-1124

14. Chen C, Lo Z, Huang Z, Inoue K, Cheng TO (1988) Percutaneous transseptal balloon mitral valvuloplasty: The Chinese experience in 30 patients. Am Heart J 115:937-947

15. Nobuyoshi M, Hamasaki N, Kimura T, Nosaka H, Yokoi H, Yasumoto H, Horiuchi H, Nakashima H, Shindo T, Mori T, Miyamoto A, Inoue K (1989) Indications, complications, and short-term clinical outcome of percutaneous transvenous mitral commissurotomy. Circulation 80:782792

16. Hung J, Chern M, Wu J, Fu M, Yeh K, Wu Y, Cherng W, Chua S, Le C (1991) Short- and long-term results of catheter balloon percutaneous transvenous mitral commissurotomy. Am J Cardiol 67:854-862

17. Inoue K, Miyamoto N, Owaki T, Nakamura T, Kitamura F (1984) Clinical application of transvenous mitral commissurotomy by a new balloon catheter. J Thorac Cardiovasc Surg 87:394-402

18. Feldman T, Caroll JD, Isner JM, Chisholm RJ, Holmes DR, Massumi A, Pichard AD, Herrmann HC, Stertzer SH, O'Neill WW, Dorros G, Sundram P, Bashore TM, Ramaswamy K, Jones LS, Inoue K (1992) Effect of valve deformity on results and mitral regurgitation after Inoue balloon commissurotomy. Circulation 85:180-187

19. Rocha P, Berland J, Lefebvre JM, Strumza P, Lacombe P, Fernandez F (1992) Inoue balloon usefulness in case of failure to stabilize bifoil balloon during percutaneous mitral valvotomy. Cathet Cardiovasc Diagn 26:323-326

20. Chen W, Chen M, Liau C, Wu C, Lee Y (1992) Safety of percutaneous transvenous mitral commissurotomy in patients with mitral stenosis and thrombus in the left atrial appendage. Am J Cardiol 70:117-119

21. Stefanidis C, Stratos C, Pitsavos C, Kallikazaros I, Triposisiades F, Trikas A, Vlachapoulos C, Gavaliatsis I, Toutouzas P (1992) Retrograde non-transseptal balloon mitral valvuloplasty: Immediate results and Iong-term follow-up. Circulation 85:1760-1767

22. Burton PD (1988) Imaging of the aging brain. Radiology 166:785-796

23. Kirkpatrick JB, Hayman LA (1987) White-matter lesions in MR imaging of clinically healthy brains of elderly subjects: Possible pathologic basis. Radiology 162:509-511

24. Daley R, Mattingly TW, Holt CL, Bland EF, White PD (1951) Systemic arterial embolism in rheumatic disease. Am Heart $\mathbf{J} 42$ : $566-581$

25. Soulié P, Caramanian M, Soulié J, Bader JL, Colcher E (1969) Les embolies calcaires orificielles calcifiées du coeur gauche. Arch Mal Coeur 12:1657-1684

26. Vernhet H, Foa Torres G, Laharotte JC, Tournut P, Bierme T, Froment JC, Duquesnel J (1993) Emboles calciques cérébrales spontanées des rétrécissements aortiques calcifiés. J Neuroradiol 20:19-23 